\title{
The Role of Adult Education in Creating a Modern Way of Teaching
}

\author{
Konstantinos Boumpourekas ${ }^{1}$, Efthymios - Spyridon Georgiou ${ }^{2}$ \\ ${ }^{1}$ Faculty of Education, Department of Early Childhood Education, University of Western Macedonia, Greece. \\ ${ }^{2}$ School Spatial Planning and Development, Department Engineering, Aristotle University of Thessaloniki, Greece
}

\begin{abstract}
Adult education is the process of adult interaction in the educational process where experiences are analysed, skills and knowledge are developed. (BrookFieldst, 1968). The aim of adult education programs is to improve the quality and of educational process. A key factor contributing to the achievement of this goal is the acquisition and development of new skills of adult educators, who teach in these programs. The adult educator is the most important factor in the educational process and plays an important role in the whole learning group, in which he/she must be a team leader, a trainer, a team member, and the "audience" outside the team, in order to succeed as an adult educator. (Rogers A., 1998).
\end{abstract}

Keywords: adult educator, skills, interview.

\subsection{The Skills of an adult educator}

To begin with, it is an undeniable fact that each person's competence in a professional field is largely based on the possession and utilization of certain skills. For example, in terms of adult education the skills that an adult educator must have to successfully perform his/her educational goals is a difficult and complex matter for theoretical discussion, so analysing them is not always easy, as there is always the risk of over-simplification. The following reference and presentation of these skills is nothing more than an attempt to summarize, as far as possible, the most important of the skills that characterize, a capable and dedicated to educational progress adult educator. 


\section{The analysis}

There are five categories of required skills for an adult educator. These categories are:
1. Personality Skills
2. Professional Skills
3. Organizing Skills
4. Teaching Skills
5. Social Skills

\subsubsection{Personality Skills}

First, by personality skills we mean all those different aspects of behavior, that are the result of cultivation and of the interaction with others in society. An adult educator, like any other teacher, is important not only to have an integrated personality but also to use it in order to help the trainees through the educational process. These skills become instantly evident, when the adult educator: demonstrates patience and understanding to the needs and the worries of his/her adults' students, also shows respect for others and is friendly, although in order to achieve his/her educational goals must have experience and a great intellectual and aesthetic background.

On the other hand, an adult educator must set his/her boundaries in the classroom, in order to establish his role as an educator and not as a friend. Moreover, he/she should give initiatives to the trainees, having the ability to be open to dialogue, inspire confidence and optimism, and finally to be a trusted, commitment and honest interlocutor and educator (Granule A., 1999ss.91-99 in Roggers A., 1998).

\subsubsection{Professional Skills}

To begin with, the professional skills of an adult educator, often make the difference between the success and failure of an educational project and in order to succeed his/ her educational goals, an adult educator must have certain professional skills, such as: having very good knowledge of the subject, be very experienced and able to apply different teaching methods and be able to use them easily in the classroom. In addition, he/she has to show a keen interest in trainees individually and collectively, expressing enthusiasm for what he / she does, being creative with independent thinking and ingenuity, and finally improving himself / herself as an adult educator by attending to seminars in order to improve his professional skills.

\subsubsection{Organizing Skills}

A topic that is very important in any classroom is the organization and proper planning of the educational process, as the adult educator must organize his or her curriculum in order to achieve the educational goals he or she has set. These are usually the learning conditions that 
constitute the informal "learning contract" that is decided jointly with the trainees, who know in advance what is offered to them and what is expected of them throughout this educational process. (Rogers A., 1998).

Firstly, all educational material is valued and divided into stages / learning cycles. Before each lesson, adult educators aim for the expected learning outcomes and analyze the programs, teaching methods and teaching techniques they will use. However, this planning should be relatively flexible to facilitate the whole lesson and the learning process and be adapted to the learners' educational needs.

Finally, at the end of each lesson, the adult educator should evaluate the teaching method and curriculum design and determine whether or not it helps the trainees, based on their progress through the learning process. (Rogers A., 1998). Referring to basic teaching skills we usually expect from the adult educator:

\subsubsection{Teaching Skills}

- To analyze in depth any educational subject which derives from his or her own field of knowledge.

- To select and be able to convey the knowledge in a comprehensible way and with the related educational material, to the trainees (Rogers A., 1989 in Shon DA1985)

- To have a comprehensive and substantiated point of view of adult learners' educational needs.

- To use educational tools and techniques tailored to his/her educational goals. (Courau S., 1999)

- To enhance the active role of the group by interactive learning actions. (Kokkos A., Lionarakis A., 1998)

- To be able to offer guidance in a discerning student-centered approach. (Rogers A., 1998)

- To give learners autonomy by building on their learning or even educational experience. (learning autonomy / personalization) (Rogers J.1989)

- To stay focused on the goals and timetable he/she has set, but at the same time be flexible in order to create a balance of consistency and adaptability.

- To resolve any kind of situations and issues that may arise in a class of adult students, calmly and with a view to consensus. (Crahton P., 1994)

- To be able to properly evaluate trainees and to make only constructive criticism, because in an adult group, the quantity and quality of the knowledge is often judged by them. (Rowhtree D., 1987)

- To use any available information that may lead him/her to improve teaching skills in the future. (Shon D., 1983) 


\subsubsection{Social Skills}

As part of the educational process, trying to build relationships of trust and respect in a group of trainees is a very important procedure and is based on the adult educator's communication skills. For this reason and in order to achieve its educational goals an adult educator must:

- Provide psychological and spiritual support and guidance to trainees.

- Try to create a learning environment that is based on mutual understanding and sincerity between the two parties (Rogers A., 1998, p. 224)

- Try to motivate adults who are indifferent or even skeptical about the educational process in which they are involved.

- To be able to co-ordinate the team and assign tasks to the group according to the skills of each trainee.

- Reward each remarkable effort individually or collectively by identifying each initial learning contribution. (Kokos A., 1998).

\section{Interview with an adult educator}

Mr. K.P is a teacher, former philologist consultant, who has an extensive experience in the adult education. He gave us an interview and answer on the two questions below as an adult educator. The following questions were given to him three days before our interview in which he came in, having at his disposal and sometimes consulting his own notes.

\subsection{The progress of the interview (part 1)}

Question 1: With your experience in adult learning, which are the main characteristics of an adult learner-student in contradiction to a teenager student.

First, if we want to make an explanation of the term's adult and education, we can say that adult means a person characterized by social maturity, responsibility, self-determination and voluntary behavior. When an adult decides to participate in an educational process, wants to use pre-existing knowledge and experience to gain new knowledge and skills through active participation. He/she wants to meet his/her inner needs and enhance his/her mature selfawareness, but he/she is opposed to changes in the way knowledge is approached.

On the contrary, the minor is more receptive to the knowledge provided by his teacher. It is easier to accept whatever knowledge and method the teacher proposes, in fact he/she expects the knowledge almost passively from the teacher, while the adult considers himself/herself capable of producing knowledge without paternalistic tendencies from the adult educator. 


\subsection{The progress of the interview (part 2)}

Question 2: Could you give us some examples to identify the differences in teaching between adult and minor students' groups, also tell us a little bit about the teaching process?

To begin with, obviously there are quite a few different aspects in the approach of teaching, depending on the audience you are targeting. For example, at the first meeting in a classroom, the noise from the conversations in the minor students' group is much louder than that of the adults. Minors talk to each other about unrelated issues, while adults deal with the lesson and learning process. Furthermore, when the teacher-trainer presents the cognitive modules, different questions arise. The group of teenagers asks questions about homework or how to get extra credits or even for the upcoming exams.

On the other hand, the adult's team is interested for the duration of the lesson, the bibliography and for extra notes from the teacher that will help them through the learning procedure. In terms of understanding the learning process, minors respond positively, asking a lot of questions. On the other hand, the adult group expresses concern about the course, their available time or their pre-existing knowledge.

\section{Conclusion}

An adult educator in order to handle the educational process in a adults' group, he/she needs to have specific qualifications. These qualifications are defined in the bibliography in a number of ways:

- Sometimes they focus on the personality of an adult trainer.

- Sometimes they appear as detailed lists that refer to key issues of adult education principles and methodologies.

In addition, and without underestimating the importance of knowledge and skills, it is necessary to emphasize the importance of each teacher's point of view towards adult education.

To sum up, the differences between adult education and minor-teenage education are quite a few, but ultimately one is the primary goal of each teacher, the sharing of knowledge with responsibility, integrity and love for teaching. 

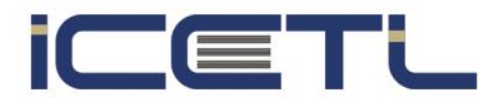

21-23 FEBRUARY, 2020 $3^{\text {rd }}$ International Conference on Research in EDUCATION, TEACHING and LEARNING

ROME, ITALY

\section{References}

[1] Jarvis P., (2004) Continuing Education and Training Theory and Practice, Alexandra Maniatis, Athens.

[2] Kokkos A., Lionarakis A., (1998). Open and Distance Education, T.B., ed.EAP, Patras.

[3] Kokkos A., (1999) Adult Education, TA, EAP ed., Patras.

[4] Rogers A., (1998) Adult Education, ed. Metaichmio, Athens.

[5] Rogers J., (1989) Adults Learning, Open University Press. 